\title{
Evaluation of maternal infusion therapy during pregnancy for fetal development
}

\author{
Dóra Petik, Erzsébet Puhó and Andrew E. Czeizel \\ Foundation for the Community Control of Hereditary Diseases, Budapest, Hungary \\ Corresponding address: Dr. Andrew E. Czeizel, 1026 Budapest, Törökvész lejtő 32. Hungary. e-mail: czeizel@interware.hu
}

Received: 2005.08.01; Accepted: 2005.08.26; Published: 2005.10.01

The aim of this project was to study the possible association between maternal infusion treatments during pregnancy and variables of fetal development as well as the occurrence of congenital abnormalities (CA) in a case-control design. The large population-based data set of the Hungarian Case-Control Surveillance of Congenital Abnormalities (HCCSCA) was evaluated based on the medically recorded infusion treatment during pregnancy. Of 22,843 case pregnant women who had newborns or fetuses with congenital abnormalities, $112(0.5 \%)$, while of 38,151 control pregnant women who had newborn infants without any defects, $262(0.7 \%)$, had infusion treatment during pregnancy. Infusion treatment was more frequent in the control group than in the case group with congenital abnormalities (adjusted POR with 945 95\% CI: 0.7, 0.6-0.9) and there was no higher rate of maternal infusion treatments in any congenital abnormality group. Mean gestational age was shorter and mean birth weight was smaller in control newborn infants without CA born to mothers with infusion treatment during pregnancy than in the babies of mothers without infusion treatment. The prevalence of mild intrauterine growth retardation was more frequent in the fetuses of pregnant women with hyperemesis gravidarum treated with infusion. The results of the study suggest that infusion treatment of pregnant women did not associate with a higher risk of congenital abnormalities. In addition, the intravenous infusion of drugs has some, but limited efficacy to prevent the adverse effects of hyperemesis gravidarum and threatened preterm delivery.

K ey words: Infusion treatment, underlying pregnancy complications, congenital abnormalities, preterm birth, intrauterine growth retardation.

\section{Introduction}

The effect of drugs during pregnancy is determined beyond the chemical structure of product, the treatment time during gestation, dose, duration of treatment, underlying diseases and pregnancy complications, other drugs due to their possible interaction and last but not least the type of administration: oral, rectal, vaginal, ophthalmic, otic, nasal, topical and parenteral [1]. Among parenteral medications, subcutaneous, intramuscular and intravenous routes can be differentiated [2]. In the latter some drugs are administered at once or by slow push, and continuous or intermittent intravenous infusion [3]. Clinical studies have shown that intravenous infusion of certain drugs is more effective than other administrations due to immediate drug action [4]; in addition, intravenous fluids are used for many sick and injured patients to treat dehydration and loss of electrolytes [5].

Infusion treatment is also used in pregnant women particularly for prolonging pregnancy in women at risk for preterm delivery [6], with extreme severe nauseavomiting (the so-called hyperemesis gravidarum) [7, 8] and after surgery large volumes of hypotonic fluid are generally given to pregnant women [9, 10]. As Friedman and Polifka [11] stated, the effect of infusion treatments during pregnancy was rarely studied for fetal development, and only the effect of specific drugs used by infusion was evaluated [12,13].

The population-based large data set of the Hungarian Case-Control Surveillance of Congenital Abnormalities (HCCSCA 1980-1996) [14] is ideal for us to check the possible association between maternal infusion therapy during pregnancy and the occurrence of congenital abnormalities (CAs), in addition to study gestational age, birth weight, the proportion of preterm birth and low birthweight in control newborn infants without CA born to mothers with or without infusion therapy.

\section{Materials and methods}

Cases

The cases with CAs for the HCCSCA were identified from the data set of the Hungarian Congenital Abnormality Registry (HCAR) [15]. Notification of cases with CAs is compulsory for physicians, and most are reported by obstetricians (in Hungary practically all deliveries occur in inpatient obstetric units and birth attendants are obstetricians) and paediatricians (who work in the neonatal units of inpatient obstetric clinics or in various inpatient and outpatient paediatric clinics). Autopsy was obligatory for all infant deaths and usual in stillborn fetuses during the study period. Pathologists sent a copy of autopsy report to the HCAR if defects were identified in stillbirths and infant deaths. The recorded total prevalence of cases with CA diagnosed from the second trimester of pregnancies through the age of one year was 35 per 1000 informative offspring (liveborn infants, stillborn fetuses and electively terminated pregnancies due to malformed fetuses) and about $90 \%$ of major CAs were reported to the HCAR during 17 years of the study period [15].

There were two restrictions at the selection of cases for the HCCSCA. Firstly, only cases that were reported during the first three months after birth or termination of pregnancy were selected. This shorter time between "pregnancy end" and data collection increases the accuracy of information about pregnancy history without undue loss of power since $77 \%$ of cases were reported during this time window to the HCAR. Secondly, three 
mild CAs (such as congenital dislocation of hip based on Ortolani click, congenital inguinal hernia, and large haemangioma), minor anomalies-variants (e.g., umbilical hernia, hydrocele, small haemangioma) and CA-syndromes of known Mendelian or chromosomal origin were excluded.

\section{Controls}

Controls were defined as newborn infants without CAs and they were selected from the National Birth Registry of the Central Statistical Office for the HCCSCA. In general, two control newborn infants were matched to every case according to sex, birth week, and district of parents' residence.

\section{Collection of exposure data}

Exposure data were obtained from the following three sources: (i) Retrospective maternal self-reported information. A post-paid questionnaire, explanatory letter along with a list of medicinal products (drugs and pregnancy supplements) and diseases, and a printed informed consent were mailed immediately after the selection of cases and controls to the mothers. The questionnaire requested information, among others, on medicinal product intakes, pregnancy complications, maternal diseases and treatments including infusion during pregnancy according to gestational month. To standardize the answers, mothers were asked to read the enclosed lists of drugs and diseases before they replied. In addition, mothers of cases were asked to give a signature for the enclosed informed consent which authorised us to record their name and address. (ii) Prospective medically recorded data. Mothers were also asked to send us the antenatal care logbook and discharge summaries of hospitalisation during pregnancy together with the filledin questionnaire and signed informed consent. The mean \pm S.D. time elapsed between the pregnancy end and return of the data package was $3.5 \pm 1.2$ and $5.2 \pm 2.9$ months in the groups of cases and controls, respectively. (iii) Supplementary data collection in non-respondent mothers. Regional district nurses were asked to visit and to question all no respondent mothers of cases and 200 no respondent control mothers at home. Regional nurses used the same questionnaire through a personal interview and evaluated the available medical records. District nurses did not visit all no respondent control mothers because the ethical committee considered this follow-up to be disturbing to the parents of these healthy children [16]. Thus, information was available on $96.3 \%$ (84.4\% from reply, $11.9 \%$ from visit) of cases and on $83.0 \%$ (82.6\% from reply, $0.4 \%$ from visit) of controls. Data from the antenatal care logbook were available in $88.4 \%$ of cases and in $93.8 \%$ of controls. The informed consent document was signed by $98.4 \%$ of case mothers. Personal identifiers (i.e. name and address) were deleted from the record of cases if their mothers did not give informed consent keep them. The personal data of controls are not recorded in the HCCSCA.

The fourth step was the evaluation of maternal infusion in five different aspects.

1) The source of information. All infusion treatments were medically recorded in the discharge summary, because pregnant women with severe nausea-vomiting and threatened preterm delivery were hospitalized.

2) Medication used through infusion and the intake of other drugs. Pregnancy supplements (such as calcium, iron, and vitamins) and infusion used for labour induction were excluded from this analysis.

3) Time of infusion according to gestational age. Gestational age was calculated from the first day of last menstrual period and three time intervals were considered: (i) the first month of pregnancy, which is before organogenesis; (ii) the second and third months of gestation, considered the most sensitive, and the so-called critical period for most major CAs; and (iii) the fourth to ninth months of gestation. If pregnant women had infusion twice or more during the study pregnancy, only one treatment was analysed according to the following priority: 2-3, 1, 4-9 months.

4) Gestational age and birth weight were analysed in newborn infants of control mothers with or without infusion treatment. These variables were also medically recorded. Cases with CAs were excluded from this analysis because CAs may have a more drastic effect for these variables than infusion treatment.

5) Potential confounding factors, as maternal age, birth order, marital and employment status of mothers (as indicators of socioeconomic status), pregnancy complications and drug uses were evaluated.

\section{Statistical analysis}

Results were analysed with the SAS version 8.02 statistical software package (SAS Institute Ins., Cary, North Caroline, USA). First, the prevalence of infusions was compared between the study groups and crude prevalence odds ratios (POR) with 95\% confidence interval $(95 \% \mathrm{CI})$ were calculated. Second, quantitative confounders such as maternal age, birth order, were compared using Student $t$ test while POR with 95\% CI were calculated for marital status and chi square test for employment status. Third, pregnancy complications were compared between case and control groups in unconditional logistic regression model. Fourth, the distribution of gestational age according to the infusion treatment was evaluated using chi square test. Fifth, the prevalence of maternal infusion treatment in 24 CAgroups was compared with the frequency of this treatment in their all matched controls and adjusted POR with $95 \% \mathrm{CI}$ for potential confounders were evaluated in a conditional logistic regression model. Sixth, the prevalence of maternal infusion treatment in the CAgroups was compared with the prevalence of this treatment in total controls as reference using unconditional logistic regression model. Finally, mean birth weight and gestational age of control newborn infants born to mothers with or without infusion treatment were compared in linear logistic regression model, while the proportion of preterm birth and low birthweight were compared in unconditional logistic regression model.

\section{Results}

During the study period, 2,146,574 babies were born in Hungary; therefore 38,151 controls represented $1.8 \%$ of the Hungarian births. In the control group, $262(0.69 \%)$ pregnant women had infusion. The case group consisted of 22,843 malformed offspring and $112(0.49 \%)$ pregnant women were treated by infusion during pregnancy. Thus the infusion treatment was less frequent in the case group (adjusted POR with 95\% CI: 0.7, 0.6-0.9).

The characteristics of mothers are shown both in total and infusion treated case and control groups in Table 
1. It is worth mentioning that pregnant women with infusion were younger with lower birth order than the mothers in the total groups. Mean maternal age did not show significant difference between case and control pregnant women with infusion, while the mean birth order was lower in the group of case mothers with infusion. There was no obvious difference in the proportion of unmarried women and in the distribution of employment status between case and control mothers with infusion.

The prevalence of pregnancy complications is shown in Table 2. These data reflect the three main reasons of maternal infusion: (i) threatened preterm delivery in about half of mothers; (ii) hyperemesis gravidarum; and (iii) surgical interventions. In addition, there was a higher prevalence of threatened abortions in the mothers with infusion compared with the mothers of total groups. However, there was no significant difference in the prevalence of pregnancy complications between the case and control groups with infusion.

The distribution of infusion according to the month of gestation in the case and controls groups is shown in Table 3. There were two peaks of infusion treatments. The first peak was connected with the treatment of hyperemesis gravidarum in the second and third months of gestation. The reason of second peak in the infusion treatments can be explained by threatened preterm delivery in the seventh and eighth month of gestation. Mothers with surgical interventions are not evaluated here because these pregnant women were evaluated previously (10). As we previously mentioned, labour induction was also excluded from this analysis. There was no significant difference in the monthly distribution of infusions between controls and cases $\left(\chi^{2}=7.55 ; \mathrm{p}=0.48\right)$ and in the frequency of infusion during the second-third months of pregnancy $\left(\chi^{2}{ }_{1}=0.4 ; p=0.51\right)$.

The reason of infusion for hyperemesis gravidarum was fluid replacement combined with oral treatment of thiethylperazine, dimenhydrinate and vitamin B6. In general Saletanol D5 ${ }^{\circledR}$ solution (sodium chloride $4.5 \mathrm{~g}$, glucose $50 \mathrm{~g}$ and alcohol $50 \mathrm{~g}$ in $1000 \mathrm{ml}$ solution with a speed of 30-40 drops/min which means $0.19 / \mathrm{bw} /$ hour of alcohol) or Ringer lactate ${ }^{\circledR}$ solution (sodium chloride 5.55 $\mathrm{g}$, potassium chloride $0.3 \mathrm{~g}$, calcium chloride $0.28 \mathrm{~g}$, magnesium chloride $0.09 \mathrm{~g}$, sodium lactate $5.04 \mathrm{~g}$ in 1000 $\mathrm{ml}$ with a speed of 120-150 drops/min) were used for this treatment. The reason of infusion for threatened preterm delivery was the so-called tocolysis, terbutaline (Bricanyl $^{\circledR}$ ) (5 mg per $1000 \mathrm{ml}$ isotonic sodium chloride solution, $1 \mathrm{ml}$ contains $5 \mu \mathrm{g}$ for $8 \mathrm{~h}$ with a starting speed of $10 \mu \mathrm{g} / \mathrm{min}$ contained by $5 \mu \mathrm{g} / \mathrm{min})$ and fenoterol (Partusisten $^{\circledR}$ ) (0.5 mg per $250-500 \mathrm{ml} 5 \%$ glucose solution with a speed of $0.5-3.0 \mu \mathrm{g} / \mathrm{min}$ ) were used for this purpose sometimes combined by verapamil (Verapamil ${ }^{\circledR}$ ).

The occurrence of other frequently used drugs (antibiotics, analgesics, etc.) did not show significant differences between case and control mothers with infusion.

The prevalence of infusion in 14 CA-groups (including 2 or more cases) was compared with the frequency of infusion in their all matched controls and adjusted POR with 95\% CI for confounding factors were calculated in conditional logistic regression model (Table 4). There was no a higher prevalence of infusion during the study pregnancy in any CA-groups. On the other hand the maternal infusion during the study pregnancy showed a lower occurrence in two CA-groups: hypospadias and multiple CAs (which include heterogeneous CA-entities). Thus, the adjusted POR with 95\% CI for the prevalence of infusion was also lower in the total group of cases with CAs. It is worth focusing the second and third months of gestation, the critical period of most major CAs. We did not find a higher prevalence of infusion treatment in any CA group, but the number of case mothers was limited.

The prevalence of maternal infusion treatment in the CA-groups was compared with the prevalence of this treatment in the total control group as well. This approach showed a higher adjusted POR with 95\% CI for renal a/dysgenesis (4.4, 1.4-14.1), however, this possible association was based on 3 cases and two offspring had mothers with infusion after the third month of gestation (i.e. the critical period of this CA-group). The lower prevalence of infusion in the mothers with children affected with hypospadias $(0.4,0.2-0.8)$ and multiple CAs $(0.2,0.1-0.8)$ was confirmed.

The distribution of gestational age and birth weight groups and their mean \pm S.D. were evaluated only in control pregnant women with or without infusion (Table 5). Both gestational age (adjusted $t=5.4, p<0.001$ ) and birth weight (adjusted $\mathrm{t}=7.6, \mathrm{p}<0.001$ ) were significantly lower in pregnant women with infusion than in pregnant women without infusion. These trends were in agreement with the higher rate of preterm birth $(16.4 \%$ vs. $9.1 \%)$ and low birthweight (12.6\% vs. $5.6 \%)$ of newborn infants born to mother with infusion.

These differences were more obvious in women who had infusion in the sixth-ninth month of gestation: mean gestational age was $38.1 \pm 2.6$ and $39.4 \pm 2.0$ week, while mean birth weight 2,941 \pm 529 and 3,277 \pm 311 gram in women with and without infusion, respectively. On the other hand the mean gestational age ( $39.4 \pm 2.5$ vs. $39.4 \pm$ 2.0 week) in control women with or without infusion was similar between the second and fifth months due to hyperemesis gravidarum. However, there was a significant reduction in mean birth weight $(3,162 \pm 596$ vs. $3,276 \pm 511$ gram) and it was reflected in a higher proportion of low birthweight (10.4\% vs. $5.7 \%)$.

\section{Discussion}

Our study is the first to evaluate the possible association in general between the effect of maternal infusion treatments during pregnancy and the different variables of fetal development. On the one hand, there was a lower prevalence of maternal infusion in the group of total CAs, and within them, of hypospadias and multiple CAs. Thus, we were not able to detect any teratogenic potential of infusion treatment during pregnancy. On the other hand, mean gestational age was shorter and mean birth weight was smaller in control newborn infants without CA born to mothers with infusion treatment during the study pregnancy than in the babies of mothers without infusion treatment. Thus, infusion of drugs used for the prevention of threatened preterm delivery seems to have a limited efficacy. However, the ratio of threatened preterm delivery was 1 in 3.6 among pregnancy complications instead of the ratio of preterm birth: 1 in 1.8, therefore nearly half of threatened preterm deliveries was effectively treated, therefore it was not inefficient. In addition, intrauterine growth retardation was found in newborn infants born to mothers with hyperemesis gravidarum on the contrary of infusion treatments. 
The strengths of the HCCSCA's data set are (i) the large and (ii) population-based cohort including 374 pregnant women with infusion treatment (iii) in an ethnically homogeneous European (Caucasian) population. (iv) The data of infusion were prospectively collected and medically recorded, thus recall bias can be excluded. (v) Cases with CA and their controls without CAs were matched, (vi) main confounders were known, (vii) birth weight and gestational age were medically recorded, and (viii) there was a good validity of CAdiagnoses due to the results of recent medical examinations [14]. However, this data set has also limitations. Though the response rate was similar in controls (83\%) and cases (84\%), there was an active followup, i.e. a home visit in all no respondent case mothers but only in 200 no respondent control mothers. However, the use of drugs in control mothers with no response did not differ significantly from the rate of control pregnant women who responded [16]. Multiple comparison may produce a statistically significant association $(\mathrm{p}<0.05)$ in every $20^{\text {th }}$ estimation because of chance and we explain the higher occurrence of renal a/dysgenesis after infusion treatment at the comparison of this CA group with the total control group by chance. In addition this possible association was based on 3 cases because only one was born to the mother who had infusion in the second month of gestation, i.e. during the critical period of renal a/dysgenesis. The type of drugs obviously has a greater impact for fetuses than the route of administration [17]. Thus it is not possible to evaluate the impact of an administration route (namely infusion in this study) without taking into account the different drugs. However, the major reason of infusion in pregnant women with hyperemesis gravidarum is the fluid replacement. The teratogenic potential of antiemetic drugs used in Hungary parallel with infusion was evaluated previously. A weak association was found between thiethylperazine and cleft lip \pm palate [18], there was no teratogenic potential of dimenhydrinate [19], while vitamin B6 showed a protective effect for cardiovascular CAs [20]. The other main indication of infusion therapy was threatened preterm delivery and it was combined with terbutaline, fenoterol and verapamil. In general the time of this treatment was the last trimester of pregnancy (i.e. after the organogenesis). We need further studies to evaluate in general the efficacy of different drugs according to administration route in pregnant women.

The intravenous route is used for the administration of medications when immediate or special drug action is required due to the severity of pathological conditions. Nevertheless, a teratogenic potential of infusion treatment and/or drugs, in addition underlying pregnancy complications (e.g. dehydration) during pregnancy was not detectable in our study. The dehydration in experimental animal (mouse) investigations caused CAs, particularly isolated cleft palate [21, 22]. In fact, mothers who had infusion treatment later delivered boys with a lower risk for hypospadias and multiple CAs. These unexpected findings need further studies.

The gestational age was shorter and birth weight was lower in control infants without CA born to mothers with infusion treatment during pregnancy. These findings may indicate the limited value of this treatment because these pregnant women had also a significantly higher proportion of preterm birth. In addition, babies born to mothers with hyperemesis gravidarum showed intrauterine growth retardation on the contrary of infusion treatment. Similar findings were not found in women with severe nausea and vomiting during pregnancy [23].

In conclusion, the results of our study suggest that infusion treatment of pregnant women did not associate with a higher risk for CAs. The intravenous infusion of drugs have some, but limited efficacy to prevent the adverse effect of hyperemesis gravidarum and threatened preterm delivery.

\section{Conflict of interest} exists.

The authors have declared that no conflict of interest

\section{References}

1. Bánhidy F, Lowry RB, Czeizel AE. Risk and benefit of drug use during pregnancy. Int J Med Sci 2005; 2: 100-106.

2. Roland M, Tozer TN. Clinical Pharmacokinetics, Concepts and Applicants, 2nd ed. London : Lee and Febiger. 1989.

3. Craig CR, Stitzel RE. Modern Pharmacology, $3^{\text {rd }}$ ed. London : Little Brown and Co. 1990.

4. Rapp PR, Elgert JF, Piecoro JJ. Guidelines for administration of commonly used intravenous drugs. Drug Intel. Clin Pharmacy 1980; 14: 193-208.

5. Winters RW. Maintain fluid therapy. In: Winter RW, editor. The Body Fluids in Pediatrics. Boston: Little Brown and Co. 1973: 113133.

6. Voelker R. Infusion helps prolong pregnancy. J Am Med Ass 1998; 279: 902-903.

7. Biggs JS. Vomiting in pregnancy. Causes and management. Drugs 1975; 9: 299-306.

8. Walters WA, Humphrey MD. Common medical disorders and their treatment. Drugs 1980; 19: 455-463.

9. Thomas TH, Morgan DB. Post-surgical hyponatraemia: the role of intravenous fluids and arginine vasopressin. Br J Surg 1979; 66: 540542.

10. Czeizel AE, Pataki T, Rockenbauer M. Reproductive outcome after exposure to surgery under anaesthesia during pregnancy. Arch Gynec Obstet 1998; 261: 193-199.

11. Friedman JM, Polifka JE. The Effects of Drugs on the Fetus and Nursing Infant. Baltimore: Johns Hopkins Univ Press. 1996.

12. Munoz FC, Marco DG, Perez AV, Caracho MM. Pregnancy outcome in a woman exposed to continuous inthrathecal baclofen infusion. Ann Pharmacother 2000; 34: 956-957.

13. Budge H, Mostyn A, Wilson V, Khong AM, Symonds ME, Stephenson T. The effect of maternal prolactin infusion during pregnancy on fetal adipose tissue development. J Endocrinol 2002; 174: 427-433.

14. Czeizel AE, Rockenbauer M, Siffel Cs, Varga E. Description and mission evaluation of the Hungarian Case-Control Surveillance of Congenital Abnormalities, 1980-1996. Teratology 2001; 63: 176-185.

15. Czeizel AE. The first 25 years of the Hungarian Congenital Abnormality Registry. Teratology 1997; 55: 299-305.

16. Czeizel AE, Petik D, Vargha P. Validation studies of drug exposures in pregnant women. Pharmacoepid Drug Safety 2003; 12: 409-416.

17. Dent NJ. Implementing International Good Practice. Buffalo: Interpharm. 1993.

18. Czeizel AE, Vargha P. Case-control study of teratogenic potential of thiethylperazine, an antiemetic drug. Br J Obstet Gynecol 2003; 110: 497-499.

19. Czeizel AE, Vargha P. A case-control study of congenital abnormality and dimenhydrinate usage during pregnancy. Arch Obstet Gynecol 2005; 271: 113-118.

20. Czeizel AE, Puhó E, Bánhidy F, Ács N. Oral pyridoxine during pregnancy. Potential protective effect for cardiovascular malformation. Clin Drug Invest 2004; 5: 259-269.

21. Brown KS, Johnston MC, Murphy PF. Isolated cleft palate in A-J mice after transitory exposure to drinking-water deprivation and low humidity in pregnancy. Teratology 1974; 9: 151-158. 
22. Schwetz BA, Nitschke KD, Staples RE. Cleft palates in $\mathrm{CF}_{1}$ mice after deprivation of water during pregnancy. Toxicol Appl Pharmacol 1977. 40: 307-315.
23. Czeizel AE, Dudás I, Puhó E. Association between severe nausea and vomiting during pregnancy and gestational age. Paediat Perinat Epid 2005; 19: 106-111.

\section{Tables}

Table 1. Characteristics of mothers

\begin{tabular}{|c|c|c|c|c|c|c|c|c|c|c|}
\hline \multirow{3}{*}{$\begin{array}{l}\text { Variables } \\
\text { Continuous } \\
\end{array}$} & \multicolumn{4}{|c|}{ Cases } & \multicolumn{4}{|c|}{ Controls } & \multirow{2}{*}{\multicolumn{2}{|c|}{$\begin{array}{l}\text { Comparison between } \\
\text { case and control mothers with } \\
\text { infusion }\end{array}$}} \\
\hline & \multicolumn{2}{|c|}{$\begin{array}{c}\text { Total } \\
(\mathrm{N}=22,843)\end{array}$} & \multicolumn{2}{|c|}{$\begin{array}{c}\text { Infusion } \\
(\mathrm{N}=112)\end{array}$} & \multicolumn{2}{|c|}{$\begin{array}{c}\text { Total } \\
(\mathrm{N}=38,151)\end{array}$} & \multicolumn{2}{|c|}{$\begin{array}{c}\text { Infusion } \\
(\mathrm{N}=262)\end{array}$} & & \\
\hline & Mean & S.D. & Mean & S.D. & Mean & S.D. & Mean & S.D. & t-test & p-value \\
\hline Maternal age, yr & 25.5 & 5.3 & 24.3 & 5.2 & 25.5 & 4.9 & 25.1 & 5.2 & 1.34 & 0.18 \\
\hline Categorical & No. & $\%$ & No. & $\%$ & No. & $\%$ & No. & $\%$ & POR & 95\%CI \\
\hline Unmarried & 1,269 & 5.6 & 9 & 8.0 & 1,471 & 3.9 & 8 & 3.1 & 2.8 & $1.0-7.4$ \\
\hline \multicolumn{11}{|l|}{ Employment status } \\
\hline Skilled worker & 6,329 & 27.7 & 30 & 26.8 & 11,690 & 30.6 & 77 & 29.4 & \multirow[t]{4}{*}{$\chi^{2}=1.19$} & \multirow{4}{*}{$p=0.95$} \\
\hline Semiskilled worker & 3,869 & 16.9 & 16 & 14.3 & 5,783 & 15.2 & 34 & 13.0 & & \\
\hline Unskilled worker & 1,503 & 6.6 & 8 & 7.1 & 1,859 & 4.9 & 14 & 5.3 & & \\
\hline Others & 4,273 & 18.7 & 18 & 16.1 & 4,332 & 11.4 & 36 & 13.7 & & \\
\hline
\end{tabular}

Table 2. Prevalence of pregnancy complications

\begin{tabular}{|c|c|c|c|c|c|c|c|c|c|c|}
\hline \multirow[t]{3}{*}{ Pregnancy complications } & \multicolumn{4}{|c|}{ Cases } & \multicolumn{4}{|c|}{ Controls } & \multirow{2}{*}{\multicolumn{2}{|c|}{$\begin{array}{c}\text { Comparison between } \\
\text { case and control mothers with } \\
\text { infusion }\end{array}$}} \\
\hline & \multicolumn{2}{|c|}{$\begin{array}{c}\text { Total } \\
(\mathrm{N}=22,843)\end{array}$} & \multicolumn{2}{|c|}{$\begin{array}{c}\text { Infusion } \\
(\mathbf{N}=112)\end{array}$} & \multicolumn{2}{|c|}{$\begin{array}{c}\text { Total } \\
(\mathbf{N}=\mathbf{3 8 , 1 5 1 )}\end{array}$} & \multicolumn{2}{|c|}{$\begin{array}{c}\text { Infusion } \\
(\mathrm{N}=262)\end{array}$} & & \\
\hline & No. & $\%$ & No. & $\%$ & No. & $\%$ & No. & $\%$ & POR & $95 \%$ CI \\
\hline Nausea-vomiting (excessive) & 1,746 & 7.6 & 33 & 29.5 & 3,869 & 10.1 & 92 & 35.1 & 0.8 & $0.5-1.2$ \\
\hline Threatened abortion & 3,501 & 15.3 & 39 & 34.8 & 6,512 & 17.1 & 81 & 30.9 & 1.2 & $0.7-1.9$ \\
\hline Preeclampsia* & 1,768 & 7.7 & 11 & 9.8 & 3,159 & 8.3 & 28 & 10.7 & 0.9 & $0.4-1.9$ \\
\hline Threatened preterm delivery & 2,603 & 11.4 & 53 & 47.3 & 5,446 & 14.3 & 135 & 51.5 & 0.8 & $0.5-1.3$ \\
\hline Placental disorders & 297 & 1.3 & 5 & 4.5 & 593 & 1.6 & 8 & 3.1 & 1.5 & $0.5-4.6$ \\
\hline Anaemia & 3,240 & 14.2 & 17 & 15.2 & 6,356 & 16.7 & 48 & 18.3 & 0.8 & $0.4-1.5$ \\
\hline Surgery & 67 & 0.3 & 4 & 3.6 & 91 & 0.2 & 12 & 4.6 & 0.8 & $0.2-2.4$ \\
\hline
\end{tabular}

*including hypertension, proteinuria and oedema alone as well

Table 3. Gestational month distribution of infusion (onset) and the name of infusion solution, in addition drugs used for treatment without infusion due to labour induction.

\begin{tabular}{|c|c|c|c|c|c|c|}
\hline \multirow[t]{2}{*}{ Gestational month } & \multicolumn{2}{|c|}{ Cases } & \multirow[t]{2}{*}{ Infusion } & \multicolumn{2}{|c|}{ Controls } & \multirow[t]{2}{*}{ Infusion } \\
\hline & No. & $\%$ & & No. & $\%$ & \\
\hline I. & 0 & 0.0 & - & 3 & 1.1 & - \\
\hline II. & 18 & 16.1 & $\begin{array}{lr}\text { Saletanol D5 } & 16, \\
\text { Ringer lactate } & 2\end{array}$ & 43 & 16.4 & $\begin{array}{l}\text { Saletanol D5 } \\
\text { Ringer lactate }\end{array}$ \\
\hline III. & 12 & 10.7 & $\begin{array}{lr}\text { Saletanol D5 } & 11, \\
\text { Ringer lactate } & 1\end{array}$ & 33 & 12.6 & $\begin{array}{c}\text { Saletanol D5 28, } \\
\text { Ringer lactate } \\
\text { Infusamine } 10 \% \\
1\end{array}$ \\
\hline IV. & 6 & 5.4 & $\begin{array}{ll}\text { Saletanol D5 } & 3, \\
\text { Fenoterol } & 2, \\
\text { Glucose } 20 \% & 1\end{array}$ & 20 & 7.6 & $\begin{array}{lr}\text { Saletanol D5 } & 12, \\
\text { Fenoterol } & 8\end{array}$ \\
\hline V. & 6 & 5.4 & $\begin{array}{ll}\text { Fenoterol } & 4, \\
\text { Terbutaline } & 2\end{array}$ & 16 & 6.1 & $\begin{array}{lr}\text { Fenoterol } & 10, \\
\text { Terbutaline } & 5, \\
\text { Glucose } 20 \% & 1\end{array}$ \\
\hline VI. & 13 & 11.6 & $\begin{array}{l}\text { Terbutaline } \\
\text { Fenoterol } \\
\text { (Verapamil 3) }\end{array}$ & 27 & 10.3 & $\begin{array}{l}\text { Terbutaline } 15, \\
\text { Fenoterol 12, } \\
\text { (Verapamil 4) }\end{array}$ \\
\hline VII. & 39 & 34.8 & $\begin{array}{l}\text { Terbutaline 27, } \\
\text { Fenoterol 12, } \\
\text { (Verapamil 4) }\end{array}$ & 69 & 26.3 & $\begin{array}{ll}\text { Terbutaline } & 41, \\
\text { Fenoterol } & 28, \\
\text { (Verapamil } & 13 \text { ) }\end{array}$ \\
\hline VIII-IX. & 18 & 16.1 & $\begin{array}{l}\text { Terbutaline } \\
\text { Fenoterol } 6 \text {, } \\
\text { (Verapamil } 6 \text { ) }\end{array}$ & 51 & 19.5 & $\begin{array}{ll}\text { Terbutaline } & 35, \\
\text { Fenoterol } & 16, \\
\text { (Verapamil } & 12 \text { ) }\end{array}$ \\
\hline Total & 112 & 100.0 & & 262 & 100.0 & \\
\hline
\end{tabular}


Table 4. Occurence of infusion in 14 CA-groups including at least two cases and in their matched controls, in addition adjusted prevalence odds ratios (POR) with $95 \%$ confidence interval $(95 \% \mathrm{CI})$

\begin{tabular}{|c|c|c|c|c|c|c|c|c|c|}
\hline \multirow{2}{*}{ Study groups } & Total & \multicolumn{3}{|c|}{ Entire pregnancy } & \multicolumn{3}{|c|}{ II-III months } \\
\cline { 2 - 10 } & No. & No. & \% & POR $^{*}$ & $\mathbf{9 5 \%}$ CI & No. & \% & POR $^{*}$ & $\mathbf{9 5 \%}$ CI \\
\hline Isolated CAs & & & & & & & & & \\
\hline Neural-tube defects & 1,202 & 2 & 0.2 & 0.5 & $0.1-2.7$ & 0 & 0.0 & - & - \\
\hline Cleft lip \pm palate & 1,374 & 10 & 0.7 & 1.3 & $0.6-3.0$ & 3 & 0.2 & 3.1 & $0.3-34.0$ \\
\hline Rectal/anal atresia/stenosis & 220 & 2 & 0.9 & 2.8 & $0.2-31.9$ & 1 & 0.5 & 1.5 & $0.1-25.6$ \\
\hline Renal a/dysgenesis & 104 & 3 & 2.9 & 2.6 & $0.5-14.7$ & 1 & 1.0 & - & - \\
\hline Obstructive urinary CAs & 502 & 3 & 0.6 & 1.0 & $0.2-4.1$ & 0 & 0.0 & - & - \\
\hline Hypospadias & 3,038 & 9 & 0.3 & 0.4 & $0.2-0.8$ & 2 & 0.1 & 0.4 & $0.1-1.9$ \\
\hline Undescended testis & 2,051 & 7 & 0.3 & 0.6 & $0.2-1.4$ & 3 & 0.2 & 1.1 & $0.2-5.1$ \\
\hline Exomphalos/gastroschisis & 238 & 2 & 0.8 & 4.5 & $0.6-35.9$ & 0 & 0.0 & - & - \\
\hline Cardiovascular CAs & 4,479 & 35 & 0.8 & 1.1 & $0.7-1.7$ & 12 & 0.3 & 1.5 & $0.7-3.3$ \\
\hline Clubfoot & 2,424 & 11 & 0.5 & 0.9 & $0.4-2.1$ & 4 & 0.2 & 0.7 & $0.2-2.4$ \\
\hline Poly/syndactyly & 1,744 & 11 & 0.6 & 1.0 & $0.5-2.2$ & 2 & 0.1 & 0.6 & $0.1-3.3$ \\
\hline CAs of musculoskeletal system & 525 & 3 & 0.6 & 0.4 & $0.1-1.6$ & 0 & 0.0 & - & - \\
\hline Other isolated CAs & 3,593 & 12 & 0.3 & 0.5 & $0.3-1.0$ & 2 & 0.1 & 0.2 & $0.0-0.7$ \\
\hline Multiple CAs & 1,349 & 2 & 0.2 & 0.1 & $0.0-0.6$ & 0 & 0.0 & - & - \\
\hline Total cases & 22,843 & 112 & 0.5 & 0.7 & $0.6-0.9$ & 30 & 0.1 & 0.7 & $0.4-1.1$ \\
\hline Total controls & 38,151 & 262 & 0.7 & & - & 76 & 0.2 & & - \\
\hline
\end{tabular}

* adjusted for maternal age ( $<25$ years, 25-29 years, and 30 years or more), birth order (first delivery or one or more previous deliveries), maternal employment status (professional, managerial, skilled worker versus semiskilled worker, unskilled worker, housewife, other), use of other drugs during pregnancy (as a dichotomous variable) and maternal disorders (as a dichotomous variable) in conditional logistic regression model

** congenital hydrocephalus, posterior cleft palate, buphthalmos, unspecified CA of ear, branchial cyst, bronchial stenosis, pyloric stenosis, stenosis of small intestine, cystic kidney, diaphragmatic CA, arthrogryposis, ichthyosis congenita

Table 5. Distribution of birth weight and gestational age groups in the control group of mothers with or without infusion

\begin{tabular}{|c|c|c|c|c|c|c|c|c|c|c|c|c|c|c|c|}
\hline \multirow{2}{*}{\multicolumn{2}{|c|}{ Gestational age (week) }} & \multirow{2}{*}{\multicolumn{2}{|c|}{-36}} & \multirow{2}{*}{\multicolumn{2}{|c|}{$37-41$}} & \multirow{2}{*}{\multicolumn{2}{|c|}{$42-$}} & \multicolumn{8}{|c|}{ Total } \\
\hline & & & & & & & & \multicolumn{4}{|c|}{ With infusion } & \multicolumn{4}{|c|}{ Without infusion } \\
\hline \multicolumn{2}{|c|}{ Birth-weight (g) } & $\begin{array}{l}\text { With } \\
\text { No. }\end{array}$ & $\begin{array}{c}\text { Withou } \\
\text { No. }\end{array}$ & $\begin{array}{l}\text { t With } \\
\text { No. }\end{array}$ & $\begin{array}{l}\text { Withou } \\
\text { No. }\end{array}$ & $\begin{array}{l}\text { With } \\
\text { No. }\end{array}$ & $\begin{array}{l}\text { Without } \\
\text { No. }\end{array}$ & No. & $\%$ & Mean & S.D. & No. & $\%$ & Mean & S.D. \\
\hline \multicolumn{2}{|l|}{-2499} & 25 & 1,258 & 8 & 825 & 0 & 51 & 33 & 12.6 & 34.4 & 3.0 & 2,134 & 5.6 & 35.7 & 3.2 \\
\hline \multicolumn{2}{|c|}{$2500-3499$} & 18 & 2,166 & 147 & 19,039 & 14 & 1,456 & 179 & 68.3 & 38.9 & 1.8 & 22,661 & 59.8 & 39.1 & 1.8 \\
\hline \multicolumn{2}{|c|}{$3500-$} & 0 & 29 & 38 & 10,736 & 1,222 & 2,329 & 50 & 19.1 & 40.7 & 1.4 & 13,094 & 34.6 & 40.5 & 1.1 \\
\hline \multirow[t]{2}{*}{ Total } & No. & 43 & 3,453 & 193 & 30,600 & 26 & 3,836 & 262 & 100.0 & 38.7 & 2.6 & 37,889 & 100.0 & 39.4 & 2.0 \\
\hline & $\%$ & 16.4 & 9.1 & 73.7 & 80.8 & 9.9 & 10.1 & & & & & & & & \\
\hline \multirow[t]{2}{*}{ Birth weight } & Mean & 2,287 & 2,486 & 3,152 & 3,325 & 3,406 & 3,617 & & & 3,035 & 571 & & & 3,278 & 511 \\
\hline & S.D. & 580 & 434 & 426 & 430 & 480 & 486 & & & & & & & & \\
\hline
\end{tabular}

Crude POR with 95\% CI for low birthweight (outcome = low birth weight, exposure = infusion): $2.4(1.7-3.5)$.

Adjusted POR for low birthweight (adjusted for birth order, maternal age and employment status, maternal disorders and use of drugs): 2.3 (1.6 - 3.4).

Crude POR with $95 \%$ CI for preterm birth (outcome = preterm birth, exposure = infusion): $2.0(1.4-2.7)$.

Adjusted POR for preterm birth (adjusted for birth order, maternal age and employment status, maternal disorders and use of drugs): 1.8 (1.3 - 2.6). 